\title{
Specification of a self-care model
}

García-Lirios Cruz, Martínez-Muñoz Enrique*, Molina-Ruiz Héctor Daniel*, Hernández-Valdés Jorge*

\begin{tabular}{|c|c|}
\hline Abstract & Resumen \\
\hline 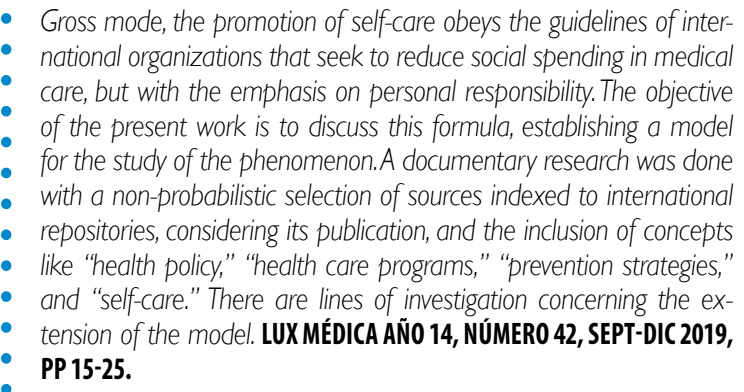 & $\begin{array}{l}\text { En términos generales, la promoción del autocuidado obedece a las } \\
\text { guías de organizaciones internacionales que buscan reducir el gasto } \\
\text { social en atención médica, pero con énfasis en la responsabilidad } \\
\text { personal. El objetivo del presente trabajo es discutir esta fórmula, } \\
\text { estableciendo un modelo para el estudio del fenómeno. Se realizó } \\
\text { una investigación documental con un muestreo no probabilistico de } \\
\text { fuentes indexadas en repositorios internacionales, considerando su } \\
\text { publicación y la inclusión de conceptos como "política de salud", "pro- } \\
\text { gramas de atención médica", "estrategias de prevención" y "autocui- } \\
\text { dado". Existen líneas de investigación sobre la extensión del modelo. } \\
\text { LUX MÉDICA AÑO 14, NÚMER0 42, SEPT-DIC 2019, PP 15-25. }\end{array}$ \\
\hline $\begin{array}{r}\text { Keywords: governance, health, disease, } \\
\text { intervention }\end{array}$ & $\begin{array}{l}\text { Palabras clave: gobernanza, salud, enfermedad, interven- } \\
\text { ción }\end{array}$ \\
\hline
\end{tabular}

\section{Introducción}

The promotion of self-care, for the purposes of this work, refers to a co-management system of health services aimed at the prevention of illnesses and accidents in the workplace, educational or family. It is a process of establishing priorities in the personal agenda, although with a view to collective or environmental public health. ${ }^{1}$

However, the promotion of self-care is distinguished by the degree of interdependence among the actors involved in the construction of a community, public and collective agenda. Unlike prevention programs and medical care strategies, the promotion of self-care implies a degree of entrepreneurship in which access and information processing is fundamental. ${ }^{2}$

This supposes differences between those who are influenced by prevention campaigns and those who assume criteria of choice for

Dr Cruz García Lirios. Profesor de la Universidad Autónoma del Estado de México, Unidad Académica Profesional Huehuetoca. E-mail cgarcia213@profesor.uaemex.mx

Dr Enrique Martínez-Muñoz Profesor de Tiempo Completo de la Universidad Autónoma del Estado de Hidalgo e-mail: emmunoz@uaeh.edu.mx M en IS Héctor Daniel Molina-Ruiz. Profesor investigador de la Universidad Autónoma del Estado de Hidalgo e-mail hmolina@uaeh.edu.mx Dr Jorge Hernández-Valdés. Profesor de la Universidad Nacional Autónoma de México email: jorheval@unam.mx

Fecha de recibido, 1 de abril de 2019

Fecha de aceptación: 1 de agosto 2019

Correspondencia Dr Cruz García Lirios Unidad Académica Profesional Huehuetoca de la Universidad Autónoma del Estado de México. Calle Nuestra Señora de los Ángeles Manzana 93 S/N, Barrio la Cañada, 54680 Huehuetoca Estado de México, México. Teléfono 5542107711 . E-mail cgarcia213@profesor.uaemex.mx 
the construction of a favorable environment for their health and that of their peers. This is the case of civil organizations dedicated to the observation of the quality of health services, but also those aimed at the construction of a system for the dissemination and transfer of knowledge to prevent the monopoly of medicines or the management of medical units or specialized centers in strategic areas. $^{3}$

In this way, self-care, within the framework of the co-governments, involves the construction of a public health system guided by a constant dialogue between users and authorities, without excluding the specialized participation of experts and medical organizations that not only affect the health policies but the local and community lifestyles. ${ }^{4}$

Precisely, in the case of dermatological health, the prevention of diseases involves the collaboration of specialists, civil society, and authorities to generate a campaign and dissemination of hygienic lifestyles, as well as immediate attention to local root problems. It is a system of co-government, governance or consensual management of financial resources and health professionals. ${ }^{5}$

The governance of dermatological health is a line of research that is part of the Division of Social Sciences, discipline of Social Work, area of specialization in adherence to the treatment of diseases and the prevention of accidents, although also the disciplines of sociology, administration, nursing, anthropology and psychology, which are participants in the diagnosis, intervention and evaluation as central axes of the public health agenda with emphasis on the prevention of health risks and the promotion of health and self-care.

\section{Theory of self-care promotion}

The theoretical frameworks that explain the promotion of self-care are: 1) theory of social reliability, 2) theory of the establishment of the agenda, 3) theory of socio-political co-responsibility.

The promotion of self-care, in the context of the three theoretical approaches, is the result of the guidelines of the Earth Summits on the effects of climate change on environmental public health, although the degree of participation of civil society establishes differences between the approaches when explaining the balance between environmental challenges and opportunities and the personal, group or collective capacities to respond to these external requirements.

Thus, promotion of self-care refers to hopelessness, according to the theory of social reliability, which warns that in the face of an environmental contingency, citizens assume the role of victim and delegate their health to their authorities. In this sense, social reliability emerges as a guiding axis of civil lifestyles, indicating the control of the government in private life concerning public health, 
as would be the case of dermatological diseases whose epidemic outbreaks can reach vulnerable sectors. ${ }^{7}$

If social reliability is indicated for the control of a pandemic, then the promotion of self-care will consist in the civil protection of the violated groups such as children, women and the elderly, but if this social reliability is accentuated in electoral contests, then it will be extended to all the sectors through proselytism and political campaigns. $^{8}$

This is a phenomenon known as the establishment of an electoral political agen$\mathrm{da}$, which explains the transition from an epidemic to a health promotion based on political leadership, candidacies, parties, and government systems. In other words, an increase in defenselessness not only generates greater reliability but also intensifies electoral contests that are no longer centered on problems of employment but health. ${ }^{1}$

In such a scenario of setting an agen$\mathrm{da}$, the differences between authorities, experts, and citizens are exacerbated since each actor develops speeches that exclude their counterparts and interlocutors. This is because health problems tend to be represented according to the information available about an epidemic or pandemic. ${ }^{4}$

Once the phenomenon has been mediated, prevention programs and strategies depend on the bias of the media when disseminating the information since, an abstract diffusion generates disinterest and a simplistic diffusion causes distrust, the media are now responsible for the preventive actions, recommendations to contain the disease or changes in lifestyles needed to eradicate the epidemic or pandemic. ${ }^{8}$

In agenda setting, experts are limited to guide the public, the rulers are exposed to media judgment and civil society is defenseless before the interests of the me- dia in reducing or intensifying information concerning the epidemic. ${ }^{8}$

In this scenario, socio-political co-responsibility is necessary, alluding to lifestyles and communication according to the prevention of diseases, but also to reduce the spread of the disease. It is in this context that the promotion of selfcare acquires more meaning because it is propaganda that is not always consistent with the media diffusion, which almost always consists in the discrediting of the authorities and the provocation of civil despair. ${ }^{7}$

If the theory of social reliability explains a high degree of defenselessness and distrust of society towards its rulers, the theory of setting the agenda exacerbates this distrust by showing that the authorities have priorities different from those of civil protection, but it is the theory of co-responsibility that will end up suggesting that the actors are participants in the construction of a public health system. ${ }^{2}$

Unlike the theory of social reliability that highlights the emergence of a sector in favor of the government in terms of health policy, the theory of co-responsibility focuses on observing opportunities and their relationship with the capacities of the actors. In a context of epidemic or pandemic, co-responsibility implies self-care to avoid contagion and the spread of the disease. ${ }^{3}$

While the agenda-setting theory focuses its interest on observing the effect of intensive media diffusion, the theory of co-responsibility warns that knowledge cannot be disseminated in the media and, in any case, should be produced by experts and not by communicators, announcers, journalists or columnists. ${ }^{4}$

Precisely, the responsible dissemination of information would not be possible to observe in communication professionals, but in health professionals who, in any case, 
would use the means to guide the strategy of civil protection or collective action. ${ }^{8}$

\section{Studies on the promotion of self-care}

Studies of the social work of dermatological health show that prevention is a lowcost factor for the treatment of a disease acquired by contamination of parasites. In this sense, a model for the study of an outbreak of dermatological contamination involves intervention strategies from social work in elementary education institutions such as the Mckendrick propagation model, although the integration of other models explains the problem of contagion and the scenarios future treatment, recontact and prevention, warning the need to carry out prevention strategies and promotion of disease-free lifestyles, as well as individual self-care as collective co-responsibility. ${ }^{1}$

The history of public health, health policies, and dermatological programs and prevention and health promotion strategies are areas of multidisciplinary research and knowledge in which social work acquires a greater relevance when establishing an approach with vulnerable groups such as the infants. ${ }^{9}$

It is estimated that the costs of treatment are higher than the prevention costs since for every peso spent in the treatment of illnesses or accident care a penny would be spent on prevention. In this sense, both areas, promotion of health and social care of diseases, pandemics or epidemics are central issues of management and administration in health policies. ${ }^{10}$

That is to say that the participation of the groups affected is increasingly significant in the measure in which they develop lifestyles and self-care strategies of their personal and collective health. Precisely, in this phase the dialogue between specialized institutions and citizens is a problematic hinge in the achievement of objectives, preparation of tasks and achievement of short, medium- and long-term goals by health professionals in general and social work in particular. ${ }^{11}$

In this way, the governance of dermatological health will be understood as a set of policies for the inclusion of governmental and social actors in the face of a public health problem such as dermatological diseases in vulnerable groups. It is a system of surveillance, monitoring and co-responsibility between the authorities and the potential victims of diseases, epidemics or pandemics. ${ }^{12}$

Unlike health policies focused on research, specialization, and treatment, the governance of dermatological health is low cost, includes all stakeholders and establishes co-responsibility agreements around objectives, tasks, and goals set in a medium-term. ${ }^{13}$

In such a scenario, the competition of public health professionals and in particular of social workers is of the utmost importance, since the strategies are disseminated in the institutions and sectors most affected by dermatological contamination. ${ }^{6}$

Exponential function models, Quetelet logistic models, Locka-Volterra function models, McKendrick propagation models, and dermatological treatment models are intervention devices for the governance of dermatological health in elementary public education institutions with emphasis on the promotion of health and self-care in vulnerable groups. ${ }^{14}$

Social work has gone from models of charity, charity, and altruism to models of diagnosis, intervention, participation, management, and co-responsibility according to health policies and targeted programs. In this sense, the models used allow the work of dermatological health promotion and the dissemination of innovations aimed at the prevention of diseases in the groups harmed. ${ }^{5}$

In the case of skin contamination by pests, the intervention of social work stands out for its ability to avoid the spread of contagion, promoting healthy lifestyles 
free of contamination, and self-care strategies. These are devices in which the social worker generates information that counteracts beliefs about the spread of diseases such as parasites. ${ }^{15}$

In principle, the exponential function model would allow the anticipation of scenarios of high contagion and health risks in a violated group. Based on these data, the social worker of an elementary health institution would promote through images the scenario of health deterioration due to the lack of hygiene and daily personal hygiene among the students. ${ }^{16}$

In the case of the Quetelet logistics model, the social work professional would generate an inventory from which potential victims of dermatological contamination would have to adopt preventive lifestyles by reducing their contact with groups at risk of contagion. In this way, the logarithmic results would allow decisions to be made against or in favor of the separation of infected groups and groups at risk, as well as the reprogramming of their activities inside or outside the classroom. ${ }^{17}$

For its part, the Locka-Volterra function model would integrate the probable exponential contamination scenarios with the effects of this contamination in the groups with the highest risk and attention to the low-risk groups. In this way, the model would allow anticipating probable scenarios of new contamination that would be confronted with a systematic and intensive diffusion of strategies of collaboration around the care of the environment for the avoidance of a new outbreak. ${ }^{18}$

Finally, the McKendrick propagation model, the model best suited for cooperation and solidarity requirements for the governance of dermatological health, includes not only the groups harmed by the disease, but also the future interaction scenarios in which new outbreaks in other groups and the re-count of the first cases would generate a scenario of high risk, but with sufficient information to reduce its exponential and logistic effects. ${ }^{19}$

Based on these models, an integral model was proposed in which the dependency relationships between contagious groups, potential contagious groups, selfcare groups, potential recontacting groups, and groups that develop new self-care and prevention styles. ${ }^{8}$

In this scenario, the intervention of social work would not only be for the promotion of health free of infection, but also the dissemination of lifestyles of self-care and cooperation in the prevention of disease. It is a collective health process in which the objective is the avoidance of a new outbreak, or, the reduction to its minimum expression. ${ }^{2}$

The contribution of this work to the state of knowledge lies in the formalization of mathematical models for the study of the governance of dermatological health in vulnerable groups. This is a discussion about the scope and limits of the models to demonstrate their usefulness decision making, the establishment of prevention programs, and dissemination of self-care styles. ${ }^{3}$

\section{| | | | | | | | | | | | | | | | | | | | | | | | | | | | | | | | | | | | | | | | | | | | | | | | | | | | | | | | | | | | | | | | | | | | | | | | | | | | | | | | | | | | | | | | | | | | | | | | | | | | | | | | | | | | | | | | | | | | | |}

\section{Methods}

A documentary research was carried out with a non-probabilistic selection of sources indexed to international repositories; Dialnet, Latindex, Publindex, Redalyc, and Scielo from 2010 to 2018, considering the search by keywords: "self-care," "risk prevention," and "health promotion," as well as those scientific and dissemination articles. The following was considered (see Table 1):

Literature type A: Information regarding the positive effects of health promotion and prevention on risk behaviors. 
Literature type B: Information regarding the positive effects of health promotion and risk prevention in self-care.
Literature type C: Information allusive to the non-effects of health promotion and risk prevention in self-care or risk behaviors.

\section{Table I}

\section{Descriptive data}

\begin{tabular}{|ccccc}
\hline & & Self-care & Promotion health & Prevention risk \\
\hline & Literature A & 25 & 21 & 18 \\
\hline & Literature B & 9 & 4 & 1 \\
\hline Dialnet & Literature C & 2 & 2 & 2 \\
\hline & Total & 36 & 27 & 21 \\
\hline & Literature A & 26 & 16 & 14 \\
\hline Latindex & Literature B & 3 & 4 & 1 \\
\hline & Literature C & 2 & 2 \\
\hline Total & 31 & 22 & 17 \\
\hline & Literature A & 20 & 11 & 10 \\
\hline & Literature B & 4 & 4 & 3 \\
\hline & Literature C & 1 & 1 & 14 \\
\hline Total & 25 & 16 & 7 \\
\hline & Literature A & 17 & 8 & 1 \\
\hline & Literature B & 4 & 2 & 0 \\
\hline Literature C & 0 & 0 & 8 \\
\hline Total & 21 & 10 & 3 \\
\hline & Literature A & 15 & 6 & 0 \\
\hline & Literature B & 2 & 1 & 0 \\
\hline & Literature C & 0 & 0 & 3 \\
\hline Total & 17 & 7 & 14 \\
\hline
\end{tabular}

Literature type A: Information regarding the positive effects of health promotion and prevention on risk behaviors. Literature type $\mathrm{B}$ : Information regarding the positive effects of health promotion and risk prevention in self-care. Literature type $\mathrm{C}$ : Information allusive to the non-effects of health promotion and risk prevention in self-care or risk behaviors. Source: Elaborated with study data

A data analysis table was used in order to infer the information, considering the Delphi technique in three feedback and qualifying rounds (see Table 2). 


\section{Table 2}

\section{Processing data}

\begin{tabular}{|c|c|c|c|c|}
\hline & Definition & Indication & Measurement & Interpretation \\
\hline Self-care & $\begin{array}{l}\text { It refers to a regimen of } \\
\text { adherence to treatment } \\
\text { and social support } \\
\text { aimed at rehabilitation. }\end{array}$ & $\begin{array}{l}\text { Data relative to } \\
\text { reduction of illnesses } \\
\text { and accidents in a } \\
\text { determined period. }\end{array}$ & $\begin{array}{l}\text { Expert judges qualified } \\
\text { informative extracts, } \\
\text { considering; }-1 \text { for } \\
\text { information unfavorable } \\
\text { to self-care, the } \\
\text { prevention of risks } \\
\text { and the promotion of } \\
\text { health, } 0 \text { for unlinked } \\
\text { contents and }+1 \text { for } \\
\text { favorable data. }\end{array}$ & $\begin{array}{l}\text { High scores refer to a } \\
\text { style of self-care }\end{array}$ \\
\hline Promotion health & $\begin{array}{l}\text { Refers to a continuous } \\
\text { self-care process } \\
\text { according to objectives, } \\
\text { tasks, and goals of a } \\
\text { risk-free regimen }\end{array}$ & $\begin{array}{l}\text { Data referring to } \\
\text { objectives, tasks and } \\
\text { goals achieved by an } \\
\text { institution in health } \\
\text { matters. }\end{array}$ & $\begin{array}{l}\text { Expert judges qualified } \\
\text { informative extracts, } \\
\text { considering; }-1 \text { for } \\
\text { information unfavorable } \\
\text { to self-care, the } \\
\text { prevention of risks } \\
\text { and the promotion of } \\
\text { health, } 0 \text { for unlinked } \\
\text { contents and }+1 \text { for } \\
\text { favorable data. }\end{array}$ & $\begin{array}{l}\text { High scores suggest } \\
\text { a health promotion } \\
\text { according to objectives. } \\
\text { tasks and goals. }\end{array}$ \\
\hline Prevention risk & $\begin{array}{l}\text { Suggests a strategy of } \\
\text { anticipation to diseases } \\
\text { and accidents. }\end{array}$ & $\begin{array}{l}\text { Data referring to } \\
\text { comparable illnesses } \\
\text { and accidents in a } \\
\text { determined period and } \\
\text { comparable to other } \\
\text { times. }\end{array}$ & $\begin{array}{l}\text { Expert judges qualified } \\
\text { informative extracts, } \\
\text { considering; }-1 \text { for } \\
\text { information unfavorable } \\
\text { to self-care, the } \\
\text { prevention of risks } \\
\text { and the promotion of } \\
\text { health, } 0 \text { for unlinked } \\
\text { contents and }+1 \text { for } \\
\text { favorable data. }\end{array}$ & $\begin{array}{l}\text { High scores suggest risk } \\
\text { prevention }\end{array}$ \\
\hline
\end{tabular}

Source: Elaborated with study data

The qualitative data analysis software (QDA) was used in order to establish the relationships between the extracts qualified by the judges with respect to the main categories established in the state of the question.
The qualifications were captured in an excel data analysis matrix, the contingency tables and independence relationships or significant dependence were estimated with the non-parametric chi-square test.

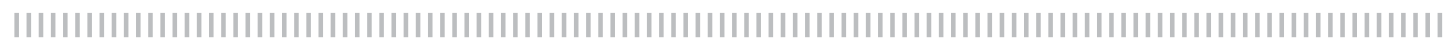

\section{Results}

Table 3 shows the descriptive values that ference relation by the processing of the suggest significant learning when relating answers of the judges in three rounds of the excerpts with the categories, the in- feedback. 


\section{Table 3}

\section{Descriptive values of the instrument}

\begin{tabular}{|c|c|c|c|c|c|c|c|c|c|c|c|c|c|}
\hline $\mathrm{E}$ & $M$ & D & $S$ & A & & C1 & & & $\mathrm{C} 2$ & & & $\mathrm{C} 3$ & \\
\hline R1 & & & & & $\chi^{2}$ & $\mathrm{df}$ & $p$ & $\chi^{2}$ & $\mathrm{df}$ & $p$ & $\chi^{2}$ & $\mathrm{df}$ & $p$ \\
\hline E1 & 0,65 & 0,15 & 0,12 & 0,14 & 14,23 & 13 & $<, 05$ & 12,13 & 13 & $<, 05$ & 12,14 & 13 & ns \\
\hline E2 & 0,69 & 0,13 & 0,14 & 0,15 & 14,29 & 12 & ns & 14,24 & 14 & ns & 14,35 & 12 & ns \\
\hline E3 & 0,66 & 0,18 & 0,15 & 0,10 & 14,30 & 15 & $<, 05$ & 15,40 & 12 & ns & 11,01 & 14 & $<, 05$ \\
\hline E4 & 0,60 & 0,10 & 0,11 & 0,11 & 15,48 & 14 & ns & 14,36 & 13 & ns & 15,46 & 15 & ns \\
\hline E5 & 0,63 & 0,19 & 0,10 & 0,13 & 15,36 & 13 & ns & 15,49 & 15 & ns & 10,36 & 12 & ns \\
\hline \multicolumn{14}{|l|}{$\mathrm{R} 2$} \\
\hline $\mathrm{E} 1$ & 0,61 & 0,13 & 0,18 & 0,19 & 15,40 & 10 & ns & 14,30 & 10 & $<, 05$ & 14,38 & 14 & $<, 05$ \\
\hline E2 & 0,62 & 0,12 & 0,10 & 0,17 & 15,26 & 11 & $\mathrm{~ns}$ & 12,31 & 11 & ns & 15,49 & 13 & ns \\
\hline E3 & 0,64 & 0,11 & 0,15 & 0,15 & 14,37 & 14 & $<, 05$ & 11,35 & 14 & $<, 05$ & 13,62 & 15 & $<, 05$ \\
\hline E4 & 0,69 & 0,14 & 0,17 & 0,14 & 13,13 & 13 & $<, 05$ & 10,43 & 19 & ns & 11.31 & 14 & ns \\
\hline E5 & 0,62 & 0,15 & 0,14 & 0,13 & 10,43 & 16 & $<, 05$ & 14,31 & 10 & ns & 13,24 & 16 & ns \\
\hline \multicolumn{14}{|l|}{ R3 } \\
\hline E1 & 0,64 & 0,11 & 0,13 & 0,13 & 13,25 & 11 & ns & 10,50 & 14 & $<, 05$ & 10,45 & 16 & $<, 05$ \\
\hline E2 & 0,61 & 0,10 & 0,14 & 0,12 & 10,58 & 13 & $<, 05$ & 15,49 & 13 & ns & 13,64 & 14 & ns \\
\hline E3 & 0,63 & 0,18 & 0,10 & 0,14 & 15,49 & 14 & $<, 05$ & 14,38 & 15 & $<, 05$ & 14,36 & 13 & $<, 05$ \\
\hline E4 & 0,60 & 0,19 & 0,18 & 0,18 & 14,30 & 15 & $<, 05$ & 13,29 & 17 & ns & 14,38 & 15 & $<, 05$ \\
\hline E5 & 0,68 & 0,13 & 0,10 & 0,10 & 15,27 & 16 & $<, 05$ & 13,20 & 10 & $<, 05$ & 14,59 & 16 & $<, 05$ \\
\hline
\end{tabular}

$E=$ Extract,$R=$ Round, $M=$ Mean,$D=$ Standard Deviation, $S=$ Swedness, $A=$ Asymmetric, $C=$ Category: $C 1=$ Self-care, $C 2=$ Promoting Health, $C 3=$ Prevention Risk; $\chi^{2}=$ chi squared, $d f=$ Degrees of freedom, $p$ $=$ significance level, $n s=$ non significance

Source: Elaborated with study data

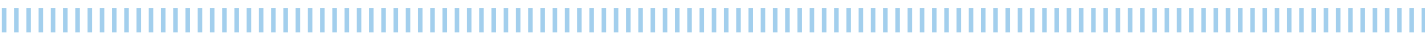

It is possible to notice a change from the first to the second and third round in which the consensus in the answers of the judges is reflected in the significant relationship between the qualified extracts and the main categories of analysis.

\section{Discussion}

The contribution of this work to the current status lies in the establishment of axes and discussion topics around self-care, considering a review period, although the design of the research limits the scope of the proposal, it is possible to warn the prevalence of three categories of analysis that allow the specification of a model for the study of the phenomenon.
A model is a representation of the relationships between the factors used in the theoretical, conceptual, and empirical review.

The promotion of self-care, indicated by the reliability, the setting of the agenda, and the co-responsibility, supposes emotional and rational processing of the information concerning a public health problem such as an epidemic or pandemic. This is so because although it is a biochemical phenomenon, it becomes a matter of public health by involving political and civil actors in the objectives, tasks, and goals of health professionals, who can have access to the media, but are replaced by communicators, journalists, drivers, reporters, colum- 
nists, or informants about the public health problem (hypothesis 1 ).

In such a scenario, the social reliability that consists of excessive trust and delegation of decision-making power to the authorities intensifies, reflecting an asymmetry between the rulers and the governed in terms of civil protection, sanitary enclosures, or medical attention. This is a context in which public health and the promotion of self-care are attributed to state institutions, but the media are responsible for discrediting to suit their audience interests (hypothesis 1a).

In this way, exacerbated social reliability generates issues such as the vulnerability of civil society to the corruption of its officials, authorities, and directors of health institutions. It is about setting an agenda biased by the media dissemination of information, almost always focused on state corruption and civil despair, which discredits the actors and generates a vacuum of expectations (hypothesis 1b).

However, such a context is ideal for co-responsibility to emerge as a value and norm for those involved. This is a series of actions aimed at assuming a responsible function according to the degree of knowledge and access to the media in which an ideal scenario is the promotion of healthy lifestyles by experts (hypothesis 1c).

Regarding the theoretical, conceptual and empirical frameworks, which highlight the role of reliability, the agenda, and co-responsibility, this work has integrated each of the three factors, but has reduced its application to a very specific context in which the civil society is dependent on its governments to be exposed to the media that disseminate a scenario of prevailing risk, threat, and uncertainty.

Therefore, it is necessary to carry out a study that includes other factors related to state institutionalism and civil participation in prevention campaigns as well as immediate attention to vulnerable groups. Also, it is advisable to include approximations that explain human behavior in situations of a health crisis, or else, theories that describe government action in the face of scarce resources.

Regarding the work of Carreón et al., (2017) 4 in which identity is the hegemonic factor to explain the effects of public health on individual lifestyles, this work warns that the promotion of self-care is a public issue, and as such, it is necessary to involve other non-civil or governmental actors to explain the complexity of a public health system.

However, it is advisable to include the theory of social identity in the model to expand the scope of the model to communities that are distinguished by their degree of attachment to the place, their rootedness to the origin and their sense of community.

In contrast, the work of García et al., (2017) 4 in which the adherence to treatment is the key factor of coincidence among experts, authorities, and citizens, the present work warns that social reliability is an adherence to the exaggerated treatment of users of the medical service with respect to their authorities. In that sense, the exclusion of citizens from their own personal and collective health presupposes an agenda focused on state protection and biomedical care, avoiding the importance of the family in treatment or rehabilitation.

However, it is necessary to include adherence to treatment as an indicator of sociopolitical reliability since both show a scenario of dependence of citizenship with respect to knowledge or management of community or public health services.

If the dependence of civil society on public health institutions consists of medical attention in the face of a contingency and this is reflected in the degree of social reliability as in the adherence to treatment, then the cases of older adults, as groups that are violated, should explain the causes of such dependence. 
García et al., (2017) ${ }^{6}$ showed that the differences between representations of youth, referring to an exacerbated confidence in the vigor and the presumption of risks, with respect to the representations of old age, indicated by an increase in fatigue and a decrease in the capacity to react, explain the dependence of groups that have been violated.
In the present work, we prefer to look at reliability as a prelude to the establishment of an agenda that, in symbolic terms, reflects the priorities of the actors with regard to a public health problem, although the incorporation of the representation factor is recommended to explain the origin of social reliability in terms of health contingencies and hegemony of the corresponding institutions in the promotion of self-care.

\section{Conclusions}

The contribution of the present work to the state of the question consists in the specification of a model for the study of self-care promotion as a result of a conglomeration of factors that influence health policies and strategies in the face of an epidemic contingency.

The results show a peel of the promotion and prevention of risks centered on self-care, but they ignore the institutional, organizational government that supposes a public administration of integral health, interdisciplinary expert dialogue, as well as proximity to the needs, expectations, and social demands mostly felt.

However, the type of selection and the type of information analysis limit the contrast of the model to a specific context, which would not include other variables such as knowledge management, production, and transfer. It is recommended the extension and deepening of the research from international repositories such as EBSCO, Copernicus and Scopus, as well as the use of text mining to sophisticate the analysis and to be able to elaborate a model applicable to contexts and samples different from the one described in the present work.

\section{References}

1. Bautista, M., Delgado, MA, García, C., Valdés, O., Hernández, G., Castro, A. and Trujillo, KV (2016). Contrasting a model of organizational culture in community health centers before the dissemination of information on HIV / AIDS from Social Work. Teaching and Research in Psychology, 21 (3), 248-255

2. Carreón, J., Bustos, JM, Hernández, J., Quintero, ML, García, C. (2015). Reliability and validity of an instrument that measures attitude toward groups close to HIV / AIDS carriers. Eureka, 12 (2), 218-230

3. Carreón, J., Bautista, M., García, C., Hernández, G., Sandoval, FR, Pérez, G. and Valdés, O. (2016). Reliability and validity of an instrument that measures perceptions of occupational health in migrants from Huehuetoca, State of Mexico. Obets, 11 (2), 569581
4. Carreón, J., Hernández, J., Bustos, JM and García, C. (2017). Reliability and validity of an instrument that measures the commitment of social workers in community assistance institutions. Crossroads, 26, 69-86

5. García, C., Carreón, J. and Hernández, J. (2014). Contrast of a model of labor commitment in public health centers. Acata Universitaria, 24 (1), 48-59

6. García, C., Carreón, J. and Bustos, JM (2017). Occupational health of older adults in the electoral context of a city in Mexico City. Doxa, 7 (12), 36-49

7. García, C., Carreón, J., Sandoval, FJ, Bustos, JM and Aguilar, JA (2016). Structure of the work culture in a public health institution. Arequipa, 6 (1), 291-304

8. García, C., Carreón, J. and Hernández, J. (2017). Limits of occupational health models. Study of adherence to the treatment of asthma in elderly migrant workers of the State of Mexico. Management Vision, $16,103-118$ 
9. Abreu, MA (2009). Social health work in primary health care. Nursing, 3 (2), 70-79

10. Carballeda, AJ (2004). The intervention in the social, exclusion and integration in the new social scenarios. Buenos Aires: Paidós.

11. Carballeda, AJ (2006). Social Work from a historical perspective focused on intervention. From the order of bodies to the outbreak of society. Buenos Aires: Paidós.

12. Carballeda, AJ (2008). The fragmented bodies. Social intervention in the scenarios of exclusion and disenchantment. Buenos Aires: Paidós.

13. Cheeran, M. and Renjith, G. (2015). Scope of social work profession in industrial establishment. International Journal of Advances Research in Management and Social Sciences, 4 (8), 315-326

14. Valdés, O., Vilchis, FJ, Bautista, M., García, C and Castro, A. (2017). Adherence to the treatment of chronic renal failure in a community in the State of Mexico. Margin, 84, 1-14

15. Reid, P. (2006). The purpose of a school of social work. An American perspective. Social Work Education, 25 (5), 461-484 http://doi. org/10.1080/02615470600738817

16. Ribeiro, M., López, R. and Mancinas, S. (2007). Social work and social policy in Mexico. International Journal of Social Sciences and Humanities, 17 (2), 175-200

17. Walker, S. (2015). The pendulum swings back: relationship based social work in England then and now. Journal of International Scientific Publications, 13, 49-56

18. Way, M. (2013). Feminist theory, lesbian parents and social work. Synchrony, 17 (63), 1-20

19. Raudava, C. (2013). The for developing the profession of social work in the post-communist context. European Scientific Journal, 9 (20), 12-30 